\title{
Erratum to: Endotoxin adsorption therapy using polymyxin B-immobilized fiber as a treatment for septic shock-associated severe acute cholangitis
}

Yoshihiro Inoue $\cdot$ Yasuhisa Fujino $\cdot$ Makoto Onodera •

Satoshi Kikuchi $\cdot$ Masayuki Sato $\cdot$ Gaku Takahashi ·

Masahiro Kojika $\cdot$ Shigeatsu Endo

Published online: 1 October 2013

(C) Springer Japan 2013

Erratum to: Clin J Gastroenterol

DOI 10.1007/s12328-013-0411-0

Unfortunately, the original version of this article did not include the name of the following author:

Masayuki Sato

Department of Critical Care Medicine, Iwate Medical University, Morioka, Iwate

The online version of the original article can be found under doi:10.1007/s12328-013-0411-0.

Y. Inoue · Y. Fujino $(\bowtie) \cdot$ M. Onodera $\cdot$ S. Kikuchi · M. Sato · G. Takahashi - M. Kojika · S. Endo

Department of Critical Care Medicine, Iwate Medical University, 19-1 Uchimaru, Morioka, Iwate 020-8505, Japan

e-mail: yfujino-gi@umin.ac.jp 